\title{
Adverse effects of stromal vascular fraction during regenerative treatment of the intervertebral disc: observations in a goat model
}

\author{
Suzanne E. L. Detiger • Marco N. Helder • \\ Theodoor H. Smit · Roel J. W. Hoogendoorn
}

Received: 6 June 2014/Revised: 6 February 2015/ Accepted: 6 February 2015/Published online: 15 February 2015

(C) The Author(s) 2015. This article is published with open access at Springerlink.com

\begin{abstract}
Stromal vascular fraction (SVF), an adipose tissue-derived heterogeneous cell mixture containing, among others, multipotent adipose stromal cells (ASCs) and erythrocytes, has proved beneficial for a wide range of applications in regenerative medicine. We sought to establish intervertebral disc (IVD) regeneration by injecting SVF intradiscally during a one-step surgical procedure in an enzymatically (Chondroitinase $\mathrm{ABC}$; $\mathrm{CABC}$ ) induced goat model of disc degeneration. Unexpectedly, we observed a severe inflammatory response that has not been described before, including massive lymphocyte infiltration, neovascularisation and endplate destruction. A second study investigated two main suspects for these adverse effects: cABC and erythrocytes within SVF. The same destructive response was observed in healthy goat discs injected with SVF, thereby eliminating $\mathrm{cABC}$ as a cause. Density gradient removal of erythrocytes and ASCs purified by culturing did not lead to adverse effects. Following these observations, we incorporated an extra washing step in the SVF harvesting protocol. In a third study, we applied this protocol in a one-step procedure to a goat herniation model, in which no adverse responses were observed
\end{abstract}

S. E. L. Detiger · M. N. Helder · T. H. Smit ( $₫)$.

R. J. W. Hoogendoorn

Department of Orthopaedic Surgery, VU University Medical

Center, De Boelelaan 1117, 1081 HV Amsterdam,

The Netherlands

e-mail: th.smit@vumc.nl

S. E. L. Detiger

e-mail: s.detiger@vumc.nl

S. E. L. Detiger - M. N. Helder - T. H. Smit

Center for Translational Regenerative Medicine (CTRM)

and MOVE Research Institute Amsterdam, Amsterdam,

The Netherlands either. However, upon intradiscal injection of an identically processed SVF mixture into our goat IVD degeneration model during a fourth study, the adverse effects surprisingly occurred again. Despite our quest for the responsible agent, we eventually could not identify the mechanism through which the observed destructive responses occurred. Although we cannot exclude that the adverse effects are species-dependent or model-specific, we advertise caution with the clinical application of autologous SVF injections into the IVD until the responsible agent(s) are identified.

Keywords Stromal vascular fraction - Animal model . Intervertebral disc - Degeneration - Adipose stem cells

\section{Introduction}

A comprehensive number of diseases and degenerative conditions have recently been treated successfully with stromal vascular fraction (SVF), a mixture of various cell types derived from adipose tissue. Besides multipotent stromal cells, this heterogeneous cell mixture has been reported to contain endothelial cells, pericytes and hematopoietic cells (monocytes, lymphocytes and granulocytes) [1] (Table 1). Also, large numbers of erythrocytes are present in this mixture, despite several washing steps $\left(10^{8}-10^{9}\right.$ cells per $\mathrm{ml}$ compared to $5 \times 10^{9}$ erythrocytes per $\mathrm{ml}$ whole blood). In addition to soft tissue applications such as pulmonary fibrosis [2] and vascular bypasses [3] that have benefited from the healing potential, musculoskeletal research groups have successfully incorporated SVF in their therapies, like for chondromalacia patellae [4]. Correspondingly, our group had thriving experiences with this cell mixture, as demonstrated in goat osteochondral 
defects [5] and a clinical trial for maxillary sinus floor reconstruction [6]. As a result, the general idea has emerged that autologous SVF could be safely and effectively applied to address a miscellaneous set of disorders.

The focus of our group lies on the treatment of intervertebral disc degeneration, a relevant clinical condition because of its reported correlation to low back pain [7]. To investigate disc degeneration in a reproducible fashion, a goat model was developed using a low dose of Chondroitinase $\mathrm{ABC}[8,9]$. This enzyme had been reported before as a method to lower intradiscal pressure by cleaving proteoglycans in high doses (1-50 units) $[10,11]$ and, in addition, to start mild disc degeneration in lower doses $(0.25$ units $/ \mathrm{ml})$ in several animal models [12, 13]. Next, we formulated a new concept in which adipose stem cells were harvested and reinserted in a single session for intervertebral disc degeneration, similar to a previously described one-step surgical procedures for other applications (Fig. 1) [5, 14, 15]. In this one-step procedure, adipose tissue is enzymatically digested, centrifuged and washed to obtain a heterogeneous mixture of cells, called the stromal vascular fraction (SVF). This fraction was injected in goat intervertebral discs, both in healthy IVDs and in discs that had been altered either by chemical degeneration using $\mathrm{CABC}$ or surgical nucleotomy.

Unexpectedly, in three out of four consecutive studies designed to evaluate the regenerative potential of SVF, we observed severe adverse events in a substantial number of discs that had been injected with autologous SVF. Infiltration with inflammatory cells was observed in the nucleus pulposus, as well as local destruction of the gross anatomy. In our search for an explanation for these adverse events, we have ruled out several potential mechanisms through which these adverse events could have occurred. Despite efforts to systematically investigate the responsible etiological factor for these adverse effects, the underlying mechanism has not yet been entirely elucidated.

Table 1 Composition of adipose-derived stromal vascular fraction (SVF) according to the International Federation for Adipose Therapeutics and Science (IFATS) and International Society for Cellular Therapy (ISCT)

Cell populations resident in SVF (\%)

$\begin{array}{ll}\text { Hematopoietic-lineage cells } & \\ \text { Stem and progenitor cells } & <0.1 \\ \text { Granulocytes } & 10-15 \\ \text { Monocytes } & 5-15 \\ \text { Lymphocytes } & 10-15 \\ \text { Endothelial cells } & 10-20 \\ \text { Pericytes } & 3-5 \\ \text { Stromal cells } & 15-30\end{array}$

Table obtained from [1]
Nevertheless, we want to share our experience with the research community and conclude that intradiscal therapies containing autologous SVF do not appear ready for application in clinical practice. Here, we present our observations after four studies in a goat model on the effects of autologous SVF in the IVD and report our efforts to identify the cause of the observed adverse events.

\section{Experiments}

First study: stromal vascular fraction injection after chemical disc degeneration

A total of twelve female adult Dutch milk goats underwent a surgical procedure to induce disc degeneration by injecting five lumbar discs through a left retroperitoneal approach with $0.25 \mathrm{U} / \mathrm{ml}$ Chondroitinase ABC (CABC; Sigma, St. Louis, MO, USA) as described before [8]. Disc degeneration was allowed to develop for 3 months, after which this study was designed as a time-oriented study. During the second surgical procedure, $\sim 100 \mathrm{~g}$ of perirenal adipose tissue was harvested and SVF was isolated as described by Zuk et al. [16] with minor modifications. The obtained adipose tissue was washed with phosphate-buffered saline (PBS) to remove the majority of red blood cells, chopped into small pieces of about $50 \mathrm{~mm}^{3}$, and the extracellular matrix was digested for $60 \mathrm{~min}$ at $37^{\circ} \mathrm{C}$ with $1 \mathrm{U}$ of collagenase ("Blendzyme", Roche Diagnostics, Brussels, Belgium) per gram adipose tissue in PBS. A single cell suspension was obtained by filtering the digested material through a $100-\mu \mathrm{m}$ mesh filter (Stokvis and Smith B.V., IJmuiden, The Netherlands) to remove tissue debris. The adipose stem cell-containing cell suspension was centrifuged at $600 \mathrm{~g}$ for $10 \mathrm{~min}$, and the pellet was resuspended in culture medium, which was composed of Dulbecco's modified eagle medium (DMEM, Gibco, Paisley, UK), supplemented with $500 \mu \mathrm{g} / \mathrm{ml}$ streptomycin sulphate (Sigma), $600 \mu \mathrm{g} / \mathrm{ml}$ penicillin (Sigma), $50 \mu \mathrm{g} / \mathrm{ml}$ gentamicin (Gibco), $2.5 \mu \mathrm{g} / \mathrm{ml}$ fungizone (Gibco), and $10 \%$ foetal bovine serum (FBS, Hyclone, Logan, UT). After centrifugation, the SVF pellet was resuspended in DMEM without additives, washed for an additional two times with PBS, and subsequently resuspended to either $10^{6}$ or $10^{7}$ cells $/ \mathrm{ml}$ PBS. In each goat, four degenerated discs were injected with $100 \mu$ l containing either $10^{5}$ or $10^{6}$ freshly isolated nucleated cells or plain PBS as a control treatment, in a randomised fashion, using a 26-Gauge needle. After wound closure, the animals were allowed to move freely with follow-up periods of $1(n=7)$ and 3 months $(n=5)$. Prior to killing, goats were sedated with $10 \mathrm{mg} / \mathrm{kg}$ ketamine intramuscularly, and lateral radiographs were obtained. Subsequently, they were euthanised 
Fig. 1 Concept of a one-step surgical procedure. The surgery starts with harvesting of the adipose tissue, followed by a split procedure. The surgeon continues the surgery, while the tissue engineer isolates the stem cell-containing cell population from the adipose tissue, treats the cells to induce differentiation into the proper phenotype (optional), and seeds the stimulated cells on the scaffold. The surgeon then implants the scaffold containing the stem cells, and finishes the surgery. The whole procedure takes approximately $2 \mathrm{~h}$

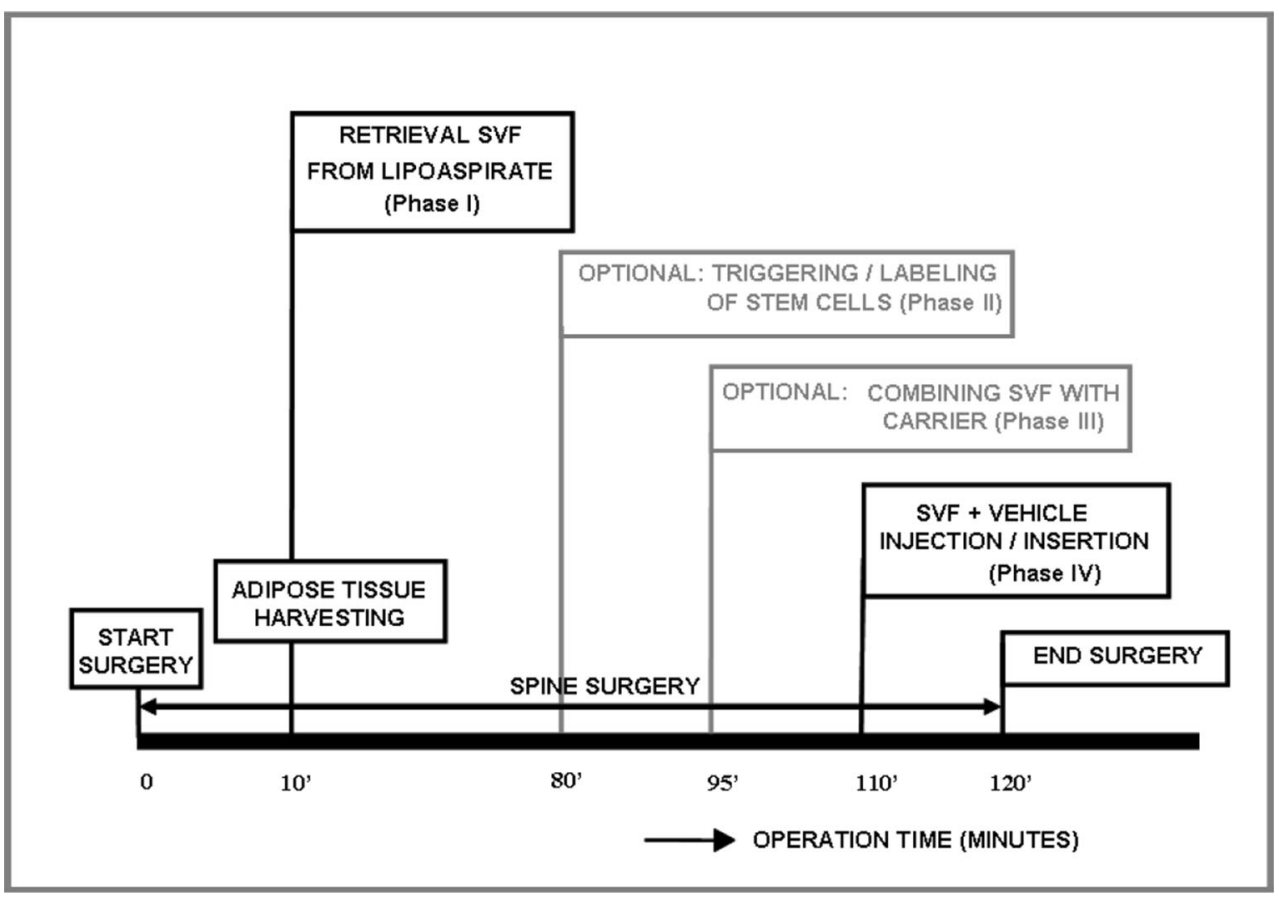

with an intravenous overdose of sodium pentobarbital (20 mg/kg), after which the lumbar spines were harvested, dissected and prepared for further analysis.

Histologically, the intervertebral discs used as sham controls had a normal appearance with concentric annular lamellae, which were easily distinguishable from the nucleus pulposus tissue (Fig. 2a). The extracellular matrix of the latter had an open structure with chondrocyte-like cells present in the matrix. The enzymatically degenerated discs injected with PBS in the second surgery (sham treatment) had a more degenerated appearance (Fig. 2b). In these discs, annular fissures were observed, as well as a condensation of the extracellular matrix of the nucleus pulposus with a decreased number of cells and a diminished demarcation between annulus fibrosus and nucleus pulposus (Fig. 2b). In 38 of 48 of the discs injected with SVF fraction, a severe inflammatory response occurred (Fig. 2c). Ten out of 14 discs injected with $10^{5}$ perirenal SVF demonstrated an inflammatory response and the same was observed in 13/14 discs injected with $10^{6}$ cells after 1 month. After three months, this response was observed in $7 / 10$ and $8 / 10$, respectively. In the central region a cellular infiltrate, mainly consisting of plasma cells and macrophages, was observed in the early phase (1 month) of the response (Fig. 2d). At the margins, neovascularisation was observed in the disc and osteoclastic activity was high at the bone-infiltrate junction (Fig. 2e). After three months, (myo)fibroblastic cells were observed in the central area where extensive remodelling (scar tissue formation/collagen deposition) occurred. This reaction was similar to the response that was observed in discs injured with higher doses of Chondroitinase ABC [8]. Also, osteoblasts were found at the margins rimming along osteoid. Simultaneously, we conducted a similar pilot study, using hyaluronic acid as a vehicle, in which we observed the same response and adverse effects (data not shown).

After this first regeneration study using autologous SVF in a goat model, two hypotheses were formulated as potential causes of the observed inflammatory response. First, residual enzyme activity of Chondroitinase $\mathrm{ABC}$ was suggested as a possible culprit for the adverse effects. Second, the reaction might have stemmed from the presence of macrophages in combination with red blood cells (RBCs) in the cell mixture. After all, RBCs had previously been reported to induce cartilage damage in the joints of haemophilia patients, resulting in haemophilic arthropathy by the iron-catalysed production of destructive oxygen metabolites [17]. To determine the trigger for the inflammatory response in our first study, an additional study was designed, in which the goal was threefold: (1) to rule out that adverse effects had been due to residual CABC activity, (2) to exclude the large number of RBCs as causing mechanism and (3) to investigate a more homogeneous stem cell fraction. For the first purpose, SVF was also injected into healthy goat discs; for the second goal, SVF was treated with a density gradient (Optiprep) to get rid of the RBCs; and third, adipose-derived stem cells (ASCs) were cultured before implantation in goat IVDs. 

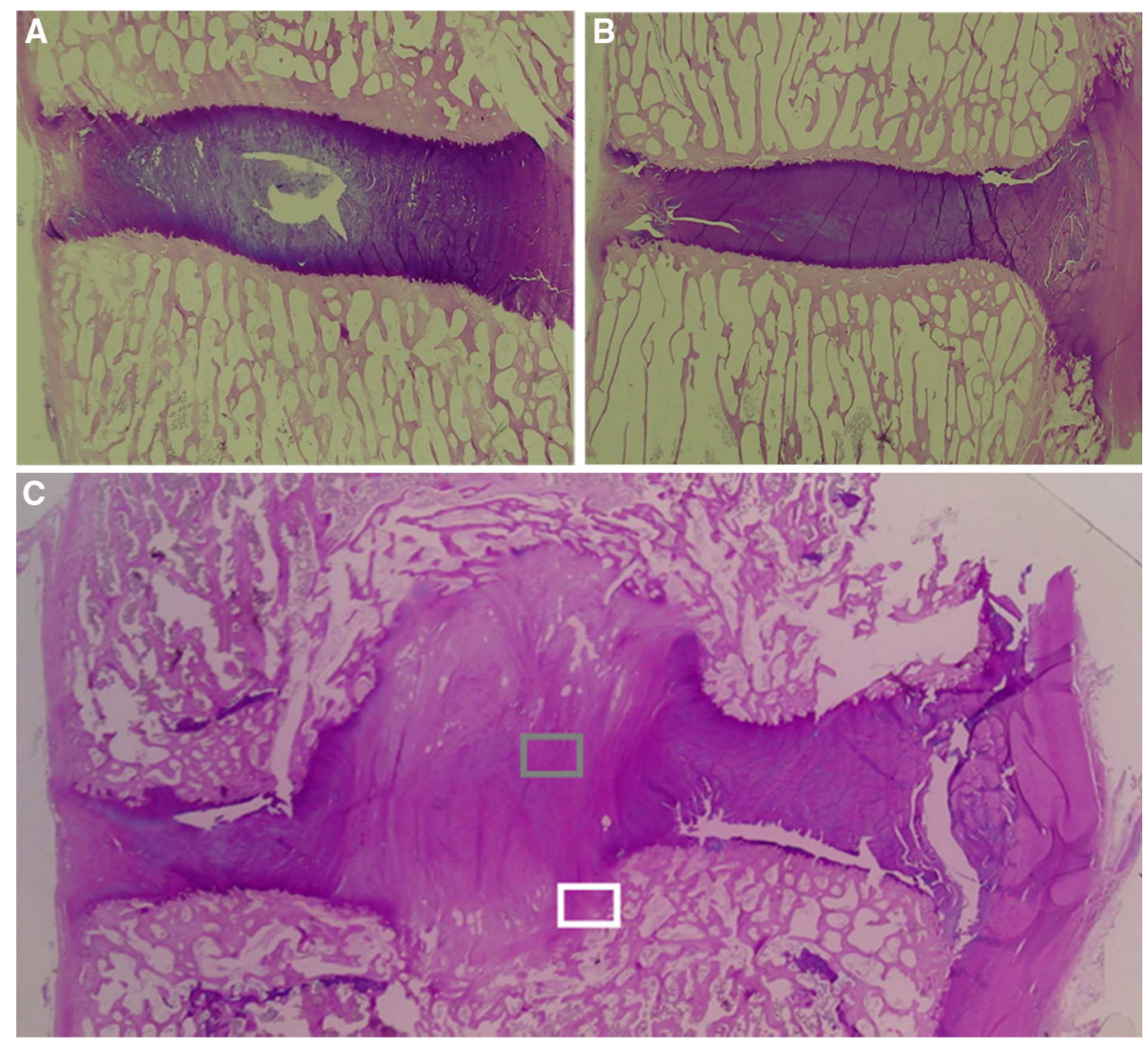

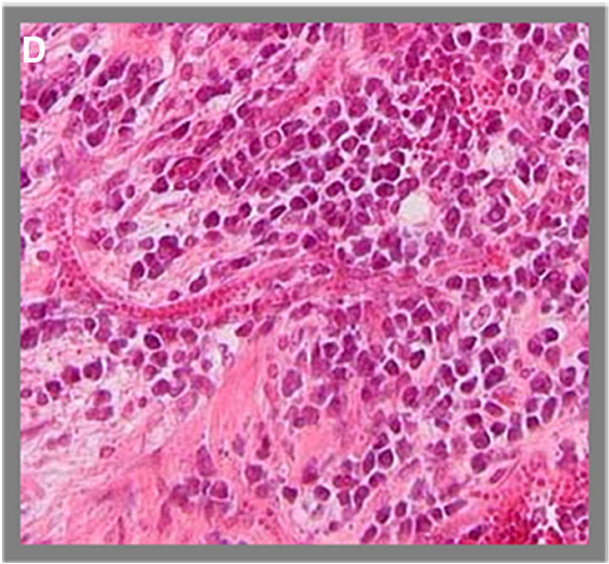

Fig. 2 a Micrograph of a paramidsagittal section of a sham-operated disc stained with AB-PAS. The disc was isolated after 1 month $(\times 1)$. There is a normal, concentric organisation of the lamellae of the annulus fibrosus (AF), the extracellular matrix (ECM) of the nucleus pulposus (NP) is proteoglycan-rich and the border between the NP and the AF is easily recognisable. b Micrograph of a paramidsagittal section of a PBS-injected disc stained with AB-PAS. The disc was collected after 1 month $(\times 1)$. This disc shows some characteristics of mild disc degeneration: the border between the NP and AF is not well defined, the ECM of the NP is denser and cracks are visible in the AF. c Micrograph of a paramidsagittal section of a stromal vascular fraction (SVF; $10^{6}$ nucleated cells $/ \mathrm{ml}$ ) injected disc stained with

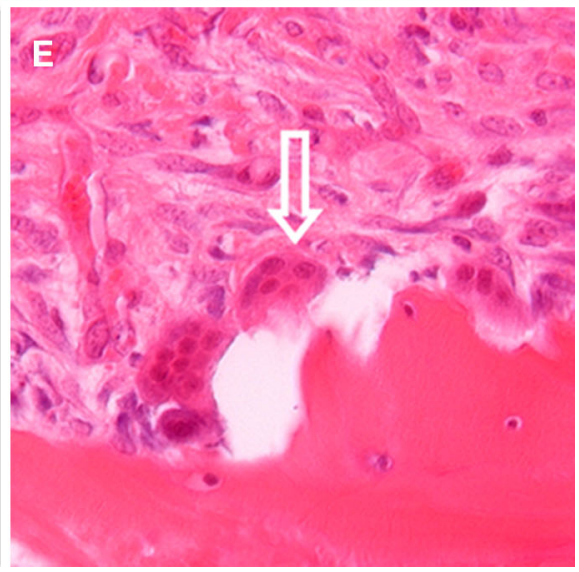

AB-PAS. Disc was collected after 1 month $(\times 1)$. The inflamed area in the NP extends into the vertebral bodies, through both endplates. Also, beginning osteophyte formation can be observed. The grey box position of micrograph $\mathbf{d}$, the white box of micrograph e. $\mathbf{d}$ Detail of a SVF $\left(10^{6}\right.$ nucleated cells $\left./ \mathrm{ml}\right)$ injected disc stained with AB-PAS after 1 month $(\times 200)$. This micrograph is a detail of the round cellular infiltrate observed in the 1-month follow-up group after injection of the disc with SVF. e Detail of a SVF $\left(10^{6}\right.$ nucleated cells $\left./ \mathrm{ml}\right)$ injected disc stained with AB-PAS after 1 month $(\times 200)$. This detail shows two osteoclasts as observed at the edges of the inflammatory response and the vertebral bodies 
Second study: healthy discs, red blood cell depletion and cultured adipose-derived stem cells

To rule out that adverse effects were due to residual CABC activity (after 3 months incubation time to develop degeneration), one healthy disc in each of six goats was injected with SVF. Furthermore, plain SVF, density gradienttreated SVF and cultured ASCs were randomly evaluated in four chemically degenerated discs, using the same goat intervertebral disc degeneration model as in the first study. For the two SVF groups (plain SVF and density gradienttreated SVF), the same protocol was followed in this second study for the harvesting of SVF. After re-suspension in DMEM without additives, the SVF was divided into two equal parts. One part was further processed as described for the first study (plain autologous SVF), whereas the other part was subjected to Optiprep ${ }^{\circledR}$ density gradient centrifugation. Optiprep ${ }^{\circledR}$ density gradient-mediated SVF purification through reduction of red blood cells (RBCs) was performed according to the manufacturer's instructions (protocol C2, Axis-shield). The mononuclear stromal vascular fraction band was collected, washed twice with PBS, and finally resuspended to $10^{6}$ nucleated cells $/ \mathrm{ml}$ in PBS. Of this cell suspension, $100 \mu \mathrm{l}$ was injected in the enzymatically degenerated discs. For the cultured ASCs group, adipose tissue had already been harvested during the degeneration induction surgery, and these cells were resuspended in culture medium and seeded in $75 \mathrm{~cm}^{2}$ culture flasks (Greiner Bio-One, Kremsmuenster, Austria). Upon confluency, adipose-derived stem cells (ASCs) were trypsinised from the culture flasks using $0.25 \%$ trypsin $/ 0.1 \%$ EDTA in PBS, harvested, and reseeded once (passage 1). After harvesting, cells were stored in liquid nitrogen until one week before reinsertion. At that time, cells were thawed, allowed to recover for one week, and finally resuspended to $10^{6}$ nucleated cells $/ \mathrm{ml}$ PBS just prior to implantation in the goat discs.

Both the healthy and the previously degenerated discs injected with plain SVF exhibited an inflammatory response similar to those described in the first study. We observed scar tissue formation in the central part of the nucleus pulposus and bone formation at the rims of the vertebrae. Discs injected with RBC-depleted SVF (Optiprep) demonstrated mild degeneration, although one disc out of six revealed similar endplate irregularities and an inflammatory response as described in the plain SVF-injected discs. CABC-degenerated discs injected with PBS showed identical results to discs injected with cultured ASCs, i.e. no inflammatory response or endplate irregularities in any disc, thus ASCs themselves showed no adverse effects at all. A regenerative response could not be identified in these discs either, although some discs did show increased numbers of nucleus pulposus-like cells [18].
This second study attempted to pinpoint the cause of the adverse events by applying (a) density gradient removal of RBCs; (b) ASCs cultured to homogeneity (to remove RBCs as well as other contaminating cell types present in SVF); and (c) injection of SVF in intact discs to rule out CABCmediated effects. It was concluded that RBCs indeed might have been the cause of the adverse effects and that the adverse effects were not due to the CABC that was used to create the degenerative disc model. Furthermore, we concluded that cultured ASCs did not regenerate the disc after mild degeneration, but neither did this treatment lead to adverse effects. In contrast, a similar experiment had been performed in a canine model, in which none of these adverse events were described [19]. This led us to the formulation of several other potential causes for the adverse events observed in our first two studies, based on the differences between our studies and the dog study, namely (a) residual collagenase activities in the SVF mixture; (b) the enzymatically induced disc degeneration, in contrast with the herniation model used in the referred study; (c) specific interaction based on the goat species used; and (d) potential cell mixture differences due to the harvest location of the adipose tissue. To investigate these newly formulated hypotheses, a third goat study was conducted.

Third study: partial nucleotomy model

During the first surgical procedure, the nucleus pulposus from three ( $n=2$ goats) or four ( $n=2$ goats) disc levels (randomly between T13-L1 and L5-L6) were partially excised under open surgical dissection. The annulus fibrosus was allowed to heal for approximately six weeks prior to disc therapy. In the second procedure, adipose tissue was harvested from both the perirenal area and a subcutaneous site, and transferred to a cell processor. Adipose tissue was weighed, transferred to tissue culture grade plastic dishes, and minced finely with scissors and/or scalpels under sterile conditions. The minced tissue was then washed with warmed Lactated Ringers, after which 1 $\mathrm{U} / \mathrm{ml}$ collagenase (CELASE $^{\mathrm{TM}}$, Cytori Therapeutics Inc, San Diego, CA, USA) was added to the tissue. After approximately $50 \mathrm{~min}$ of digestion, the digested tissue was further washed and concentrated, by spinning. One additional washing step was added in comparison with the protocol of the first two studies to further minimise residual enzyme activity. Under fluoroscopic visualisation, the appropriate test material was applied through a right-lateral approach by injection with a 25 -Gauge needle into the appropriate level as described before. The nucleotomised IVDs received 100-200 $\mu \mathrm{l}$ of hyaluronic acid vehicle mixed with either $2 \times 10^{6}$ nucleated cells $/ \mathrm{ml}$ isolated from perirenal fat (perirenal SVF), $2 \times 10^{6}$ nucleated cells $/ \mathrm{ml}$ isolated from subcutaneous fat (subcutaneous SVF) or 
hyaluronic acid vehicle with PBS (sham control) in a randomised fashion. The intact discs received $0.1 \mathrm{ml}$ of $10^{7}$ nucleated cells $/ \mathrm{ml}$ isolated from perirenal fat, $10^{7}$ nucleated cells $/ \mathrm{ml}$ isolated from subcutaneous fat or PBS in a randomised fashion. In total, 24 discs were involved in the experiment; the follow-up period was four weeks. In parallel to the animal study, characterisation of SVF from the different sources was performed including red blood cell counts, determination of ASC colony frequency and analysis of residual enzyme activity in the last PBS washing step, using caseinolytic and gelatinolytic assays.

The histological results of this third study were promising as the discs looked largely unaffected by the injection of different treatment groups. Annulus layers were still outwardly folded, no inflammatory responses, no increased cellularity, and no apparent differences between the groups were observed. Red blood cell numbers were $10^{8}-10^{9}$ cells per ml SVF and residual enzyme levels were negligibly low or even below assay baseline threshold.

After the successful elimination of adverse events in the third goat study, we concluded that adding an extra washing step to the SVF harvesting protocol had eliminated the adverse events. Furthermore, subcutaneous adipose tissue appeared to yield a higher number of ASCs per ml SVF obtained and showed similar values as described for human SVF. Therefore, in the next study design for disc regeneration, the subcutaneous harvest location was used.

Fourth study: stromal vascular fraction and bone morphogenetic protein-2

This study was performed in the context of a disc regeneration study using a newly developed hyaluronic acidfibrinogen hydrogel (ratio 1:18 w/w, MW $235 \mathrm{kDa}$, ProCore Bio Med Ltd, Ness Ziona, Israel) and BMP-2 (200 ng/ml, UHZ, Zürich, Switzerland). In seven adult Dutch milk goats, five lumbar IVDs were chemically degenerated during 3 months using $0.25 \mathrm{U} / \mathrm{ml}$ Chondroitinase $\mathrm{ABC}$. During the second procedure, subcutaneous adipose tissue was harvested and SVF was isolated, following the same protocol as described before in the previous studies. Subsequently IVDs were randomised to five intervention groups: hyaluronic acid-fibrinogen vehicle only, vehicle with SVF $\left(10^{6}\right.$ nucleated cells), vehicle with BMP-2, vehicle with both SVF and BMP-2 or no intervention. After killing at 3 months follow-up, lumbar spines were harvested for further analysis, using lateral radiographs, T2-weighted MRI, macroscopic and histological scoring.

This fourth study demonstrated once more an inflammatory response in $83 \%$ of the discs injected with autologous SVF, concurrent with severe degenerative changes in all parameters. Figure 3 shows typical examples of osteophyte formation (3a) and endplate destruction (3b) on lumbar radiographs, as well as a complete loss of morphological organisation on T2-weighted MRI (3c). Nota bene: on the MRI images, the apophyses adjacent to the endplates are still visible, as in adult goats the growth plates persist after skeletal maturity [20]. No adverse effects were observed after injection of the hydrogel alone or in combination with BMP-2 into the mildly degenerated IVDs. In particular, no osteophytes were present in the group injected with vehicle and BMP-2 only.

Macroscopically, massive scarring was observed in the SVF-injected IVDs, including endplate destruction and osteophyte formation (Fig. 4). On histological sections, scar formation, endplate destruction and inflammatory cells, including macrophages and plasma cells were observed, indicating a chronic inflammatory response. Also, neovascularisation was observed in the discs as well as osteoclasts at the interface between NP and endplates. We saw no signs of infection, such as microorganisms, neutrophil or eosinophil granulocytes. Healthy discs were characterised by a well-defined demarcation between the $\mathrm{NP}$ and $\mathrm{AF}$, organised collagen fibres and a normal gelatinous appearance of the NP matrix.

\section{Discussion}

The goal of our studies was to achieve regeneration of the intervertebral disc in a validated goat model of disc degeneration using a one-step surgical procedure with adipose-derived SVF, a heterogeneous cell mixture that has been recognised for its healing potential in various degenerative conditions. This paper primarily describes our consistent observations of a severe inflammatory response to autologous SVF injections in goat discs after prior enzymatically induced degeneration. Despite our efforts to identify the responsible etiological factor for these adverse effects, a watertight explanation for these effects did not emerge.

Several factors, however, have been ruled out by the combination of these studies. First, we refuted infection as a possible cause because of the absence of microorganisms, neutrophil and eosinophil granulocytes in histological sections. All goats were closely monitored and did not show any sign of infection, nor were there any microorganisms found in SVF cultures. With the second study, we showed that the adverse events were not caused by CABC, because the response also occurred after SVF injection in healthy discs. Also, residual collagenase activity was probably not the cause, as measured enzyme levels were very low in the third study. Furthermore, cell numbers per se seemed unlikely, as the same number of cultured 
Fig. 3 a Lumbar spine radiograph of osteophytes forming a bony bridge on the ventral side of an affected intervertebral disc. b Lumbar spine radiograph showing destruction of the bony endplates. c T2-weighted MRI of the lumbar spine in which the middle IVD has lost its normal morphological organisation. Left IVD is a normal control; right had some calcification in the centre of the nucleus pulposus
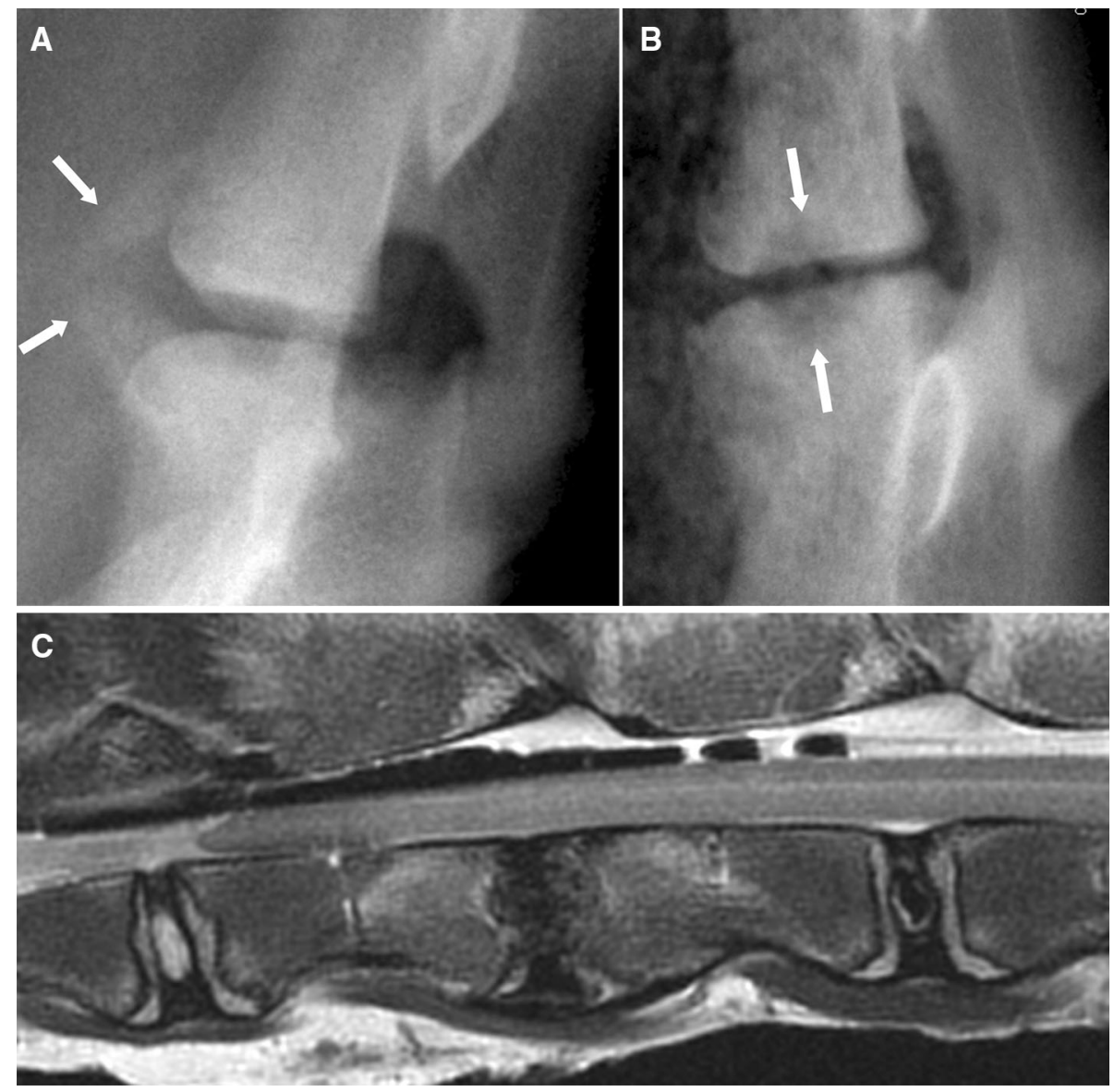

adipose-derived stem cells did not show adverse effects. Overall, we excluded infection and residual enzyme activity (both $\mathrm{CABC}$ and collagenase) as potential causing factors as well as showing that BMP-2 did not contribute to the adverse reaction. Finally, our experience with SVF has not been limited only to IVD studies, but encompasses successful application of this heterogeneous cell mixture in knee osteochondral defects, spinal fusion, and a phase I clinical trial on the use of SVF in maxillary sinus reconstruction [5, 6, 21]. These successes reject laboratory- or goat-related problems or fat harvest location as a possible culprit for the observed detrimental effects and render issues with remaining enzyme levels implausible.

Various other factors that may have contributed to the adverse effects were discussed within our group. As highlighted in the previous paragraph, injecting a large number of cells into the intervertebral disc, the largest avascular structure in the body could be considered a factor of influence. This hypothesis was substantiated by the observation in our first study, in which $10^{5}$ or $10^{6}$ nucleated cells were injected, the latter performing worse. Cultured adipose-derived stem cells injected in the same numbers, however, did not show adverse effects. On the other hand, the heterogeneous SVF cell population can only to a certain extent be compared with cultured ASCs, because it contains quite different cell types. We could speculate on the difference in cell survival within SVF: we assume that the haematopoietic and endothelial cells have a shorter lifetime in the IVD than the more robust ASCs; this would lead to more cell death in the SVF groups, which could evoke invasion of pro-inflammatory cells. ASCs, being multipotent cells, are more adaptive to the environment and may therefore stand a better chance in the harsh circumstances in the disc. Alternatively, the high shear rates when passing through a thin needle could influence the survival of various cell types differently, possibly favouring the ASCs. To rule out this theory, we checked the survival of ASCs in SVF after passing through a thin needle, after which we saw no differences compared to control (data not shown).

As a second hypothesis, the very high pressures involved in the injection of substantial volumes into the IVDs were considered. Mao et al. [22] described adverse effects following the injection of large volumes of PBS into rat tail IVDs. However, the volumes they injected (up to $3 \mu \mathrm{l}$ ) equaled the total nucleus volume of rat discs $(3.10 \mu \mathrm{l})$, whereas we only injected up to one-fifth of total nucleus volume (max. $200 \mu \mathrm{l}$ into 1,000 $\mu \mathrm{l}$ ). Moreover, the lack of degenerative signs in IVD levels injected with similar 

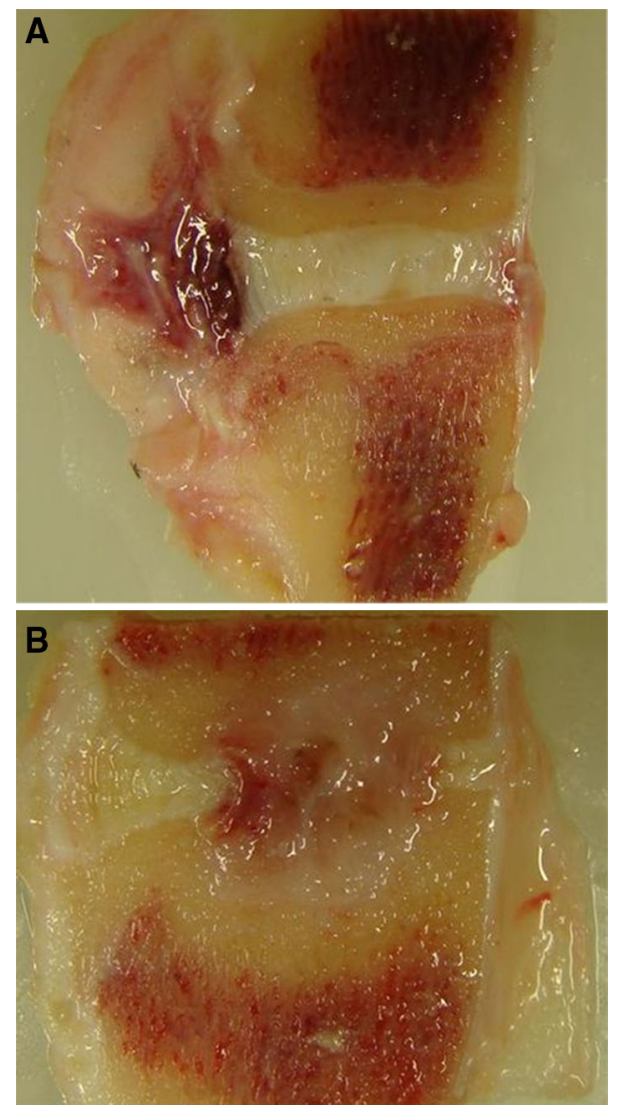

Fig. 4 a Macroscopic appearance of Fig. 3a, showing formation of osteophytes starting a bony bridge anterior of the affected IVD. b Macroscopic appearance of Fig. 3b, showing infiltration and destruction of the bony endplates with a complete loss of normal morphology

volumes of both non-cell-containing solutions and cultured ASCs rejects this hypothesis. However, a combined effect of injected cells and high intradiscal pressure, for instance, by the influx of inflammatory cells through generated micro-damage to endplates, could not be exonerated. The combination of different cell types in SVF with IVD components hypothetically might have led to another potential causative mechanism. Studies into the pathogenesis behind haemophilic arthropathy have shown that iron from red blood cells and cytokines from macrophages produce destructive oxygen metabolites that may harm the cartilage [17]. This mechanism could also be responsible for the adverse reactions we observed, as SVF contains both RBCs and macrophages while the IVD resembles a cartilaginous environment. Again, a combination of two or more different described factors cannot be excluded as potential cause.

Finally, we want to note the distinct difference between the studies with chemical degeneration using the enzyme $\mathrm{CABC}$ and the partial nucleotomy model. While the CABC model was used to induce a slow, mild degeneration over 3 months, the nucleotomy model originally aimed to mimic herniation, after which the discs were left to recover for 6 weeks. In the discs that had received nucleotomy, no adverse effects were observed after SVF injection, whereas the chemically degenerated discs were severely damaged by SVF. This difference could be explained by a difference in the surrounding tissue reaction between surgical damage and chemically induced disc degeneration. Whereas CABC causes a catabolic degenerative cascade, it could be speculated that mechanically damaged tissue after surgery has a larger tendency to recover. This anabolic state might benefit the reaction to injected agents, such as SVF, while a catabolic state is more likely to respond adversely. This could be an important clue for any future studies using intradiscal cell injections. However, we re-emphasise here that healthy discs also reacted adversely to SVF injection, which points at a mechanism that is independent of the way that discs were degenerated in the model.

Some limitations can be identified with regard to the aforementioned studies. First of all, the collagenase enzyme used in study 3 (Celase ${ }^{\mathrm{TM}}$ ) is slightly different from that of the first two goat studies. This might result in obtaining different SVF preparation with respect to the relative ratios between the ASCs and other cell types. In this regard, it is important to mention that the ASC percentages in the SVF as determined in the CFU-F assays were extremely low for the perirenal SVF preparations, and far lower than those obtained previously with Liberase Blendzyme III enzyme from Roche. Apparently, digestion conditions vary for the two sources, since Celase appeared equally effective for subcutaneous tissue when compared with Liberase (own data). Although these studies were limited by small sample sizes, due to the low number of disc levels per treatment modality, the risks of SVF injection into the IVD have been clearly established after four consecutive large animal studies.

\section{Conclusions}

In our studies, we observed a consistent, severe inflammatory response after the injection of SVF into both chemically degenerated and healthy goat IVDs, for which no definite explanation could be identified. Nevertheless, we conclude that injecting a heterogeneous mixture of cells into a healthy or degenerated IVD bears a risk for severe adverse effects. As the intervertebral disc is the largest avascular organ in the body, it can easily turn into a cellhostile environment, as opposed to other well-vascularised tissues that have proven a safe platform for SVF therapy. Therefore, based on our observations in the goat disc degeneration model, until the cause of these adverse effects is elucidated, SVF injections into the IVD may not be ready for application in clinical practice. 
Acknowledgments The authors would like to thank Doctor Timothy Ganey and Professor Hans-Jörg Meisel for their critical review of the manuscript and fruitful discussions, Klaas-Walter Meijer and Paul Sinnige for their assistance with the surgeries as well as Robert Jan Kroeze and Roderick Holewijn for help with analysing the results. Funding for this study was provided by the European Commission (FP7 project "NPmimetic"; Grant Number \#246351), ZonMw grant 40-42600-98-090 and Cytori Therapeutics, San Diego, USA.

\section{Conflict of interest None.}

Open Access This article is distributed under the terms of the Creative Commons Attribution License which permits any use, distribution, and reproduction in any medium, provided the original author(s) and the source are credited.

\section{References}

1. Bourin P, Bunnell BA, Casteilla L, Dominici M, Katz AJ, March KL, Redl H, Rubin JP, Yoshimura K, Gimble JM (2013) Stromal cells from the adipose tissue-derived stromal vascular fraction and culture expanded adipose tissue-derived stromal/stem cells: a joint statement of the International Federation for Adipose Therapeutics and Science (IFATS) and the International Society for Cellular Therapy (ISCT). Cytotherapy 15:641-648. doi:10. 1016/j.jcyt.2013.02.006

2. Tzouvelekis A, Paspaliaris V, Koliakos G, Ntolios P, Bouros E, Oikonomou A, Zissimopoulos A, Boussios N, Dardzinski B, Gritzalis D, Antoniadis A, Froudarakis M, Kolios G, Bouros D (2013) A prospective, non-randomized, no placebo-controlled, phase Ib clinical trial to study the safety of the adipose derived stromal cells-stromal vascular fraction in idiopathic pulmonary fibrosis. J Trans Med 11:171. doi:10.1186/1479-5876-11-171

3. Williams SK, Kosnik PE, Kleinert LB, Vossman EM, Lye KD, Shine MH (2013) Adipose stromal vascular fraction cells isolated using an automated point of care system improve the patency of expanded polytetrafluoroethylene vascular grafts. Tissue Eng A 19:1295-1302. doi:10.1089/ten.tea.2012.0318

4. Pak J, Lee JH, Lee SH (2013) A Novel Biological Approach to Treat Chondromalacia Patellae. PLoS One 8:e64569. doi:10. 1371/journal.pone.0064569.g004

5. Jurgens WJFM, Kroeze RJ, Zandieh-Doulabi B, van Dijk A, Renders GAP, Smit TH, van Milligen FJ, Ritt MJPF, Helder MN (2013) One-step surgical procedure for the treatment of osteochondral defects with adipose-derived stem cells in a caprine knee defect: a pilot study. Bio Res Open Access 2:315-325. doi:10.1089/biores.2013.0024

6. Farré-Guasch E, Prins H-J, Overman JR, Ten Bruggenkate CM, Schulten EAJM, Helder MN, Klein-Nulend J (2013) Human maxillary sinus floor elevation as a model for bone regeneration enabling the application of one-step surgical procedures. Tissue Eng B Rev 19:69-82. doi:10.1089/ten.TEB.2012.0404

7. Cheung KMC, Karppinen J, Chan D, Ho DWH, Song Y-Q, Sham P, Cheah KSE, Leong JCY, Luk KDK (2009) Prevalence and pattern of lumbar magnetic resonance imaging changes in a population study of one thousand forty-three individuals. Spine 34:934-940. doi:10.1097/BRS.0b013e3181a01b3f

8. Hoogendoorn RJW, Wuisman PIJM, Smit TH, Everts VE, Helder MN (2007) Experimental intervertebral disc degeneration induced by chondroitinase ABC in the goat. Spine 32:1816-1825. doi:10.1097/BRS.0b013e31811ebac5

9. Hoogendoorn RJW, Helder MN, Kroeze RJ, Bank RA, Smit TH, Wuisman PIJM (2008) Reproducible long-term disc degeneration in a large animal model. Spine 33:949-954. doi:10.1097/BRS. 0b013e31816c90f0

10. Sasaki M, Takahashi T, Miyahara K, Hirose AT (2001) Effects of chondroitinase $\mathrm{ABC}$ on intradiscal pressure in sheep: an in vivo study. Spine 26:463-468

11. Kato F, Iwata H, Mimatsu K, Miura T (1990) Experimental chemonucleolysis with chondroitinase ABC. Clin Orthop Relat Res 253:301-308

12. Norcross JP, Lester GE, Weinhold P, Dahners LE (2003) An in vivo model of degenerative disc disease. J Orthop Res 21:183-188. doi:10.1016/S0736-0266(02)00098-0

13. Boxberger JI, Auerbach JD, Sen S, Elliott DM (2008) An in vivo model of reduced nucleus pulposus glycosaminoglycan content in the rat lumbar intervertebral disc. Spine 33:146-154. doi:10. 1097/BRS.0b013e31816054f8

14. Helder MN, Knippenberg M, Klein-Nulend J, Wuisman PIJM (2007) Stem cells from adipose tissue allow challenging new concepts for regenerative medicine. Tissue Eng 13:1799-1808. doi:10.1089/ten.2006.0165

15. Hoogendoorn RJW, Lu Z, Kroeze RJ, Bank RA, Wuisman PIJM, Helder MN (2008) Adipose stem cells for intervertebral disc regeneration: current status and concepts for the future. J Cell Mol Med 12:2205-2216. doi:10.1111/j.1582-4934.2008.00291.x

16. Zuk PA, Zhu M, Mizuno H, Huang J, Futrell JW, Katz AJ, Benhaim P, Lorenz HP, Hedrick MH (2001) Multilineage cells from human adipose tissue: implications for cell-based therapies. Tissue Eng 7:211-228. doi:10.1089/107632701300062859

17. Roosendaal G, Lafeber FP (2006) Pathogenesis of haemophilic arthropathy. Haemophilia 12(Suppl 3):117-121. doi:10.1111/j. 1365-2516.2006.01268.x

18. Hoogendoorn RJW (2009) Studies on the degeneration and regeneration of the intervertebral disc. Dissertations VU University Amsterdam. elibrary.vu.nl

19. Ganey TM, Hutton WC, Moseley T, Hedrick M, Meisel HJ (2009) Intervertebral disc repair using adipose tissue-derived stem and regenerative cells: experiments in a canine model. Spine 34:2297-2304. doi:10.1097/BRS.0b013e3181a54157

20. Zhang Y, Lenart BA, Lee JK, Chen D, Shi P, Ren J, Muehleman C, Chen D, An HS (2014) Histological features of endplates of the mammalian spine: from mice to men. Spine 39:E312-E317. doi:10.1097/BRS.0000000000000174

21. Vergroesen P-PA, Kroeze RJ, Helder MN, Smit TH (2011) The use of poly(L-lactide-co-caprolactone) as a Scaffold for adipose stem cells in bone tissue engineering: application in a spinal fusion model. Macromol Biosci. doi:10.1002/mabi.201000433

22. Mao H-J, Chen Q-X, Han B, Li F-C, Feng J, Shi Z-L, Lin M, Wang J (2011) The effect of injection volume on disc degeneration in a rat tail model. Spine 36:E1062-E1069. doi:10.1097/ BRS.0b013e3182027d42 